\title{
Low susceptibility of Achatina fulica from Brazil to infection with Angiostrongylus costaricensis and $A$. cantonensis
}

\author{
Erli Neuhauss, Monaliza Fitarelli, Juliano Romanzini, Carlos Graeff-Teixeira/ ${ }^{+}$
}

Laboratório de Parasitologia Molecular, Instituto de Pesquisas Biomédicas, Pontifícia Universidade Católica do Rio Grande do Sul (PUCRS) and Laboratório de Biologia Parasitária, Faculdade de Biociências da PUCRS, Av. Ipiranga 6690, HSL $2^{\circ}$ andar, Sala 20 , 90690-900 Porto Alegre, RS, Brasil

Introduction of Achatina fulica in Brazil has led to serious concerns about its role as vector for metastrongylid worms: Angiostrongylus costaricensis and A. cantonensis. Experimental infection with both parasites was performed to evaluate the potential risk for their transmission by the giant African snail. Groups of 5 animals, both wild and bred at captivity were exposed at different inocula: 1, 5, and $10 \times 10^{3} \mathrm{~L} 1$ of A. costaricensis and A. cantonensis. In all groups, few snails got infected and parasitic burden was low. Two different ways of infection were tested: ingestion produced higher numbers of $L 3$ than the inoculation through an artificial hole in the shell. We also report the parasitological examination of 6 batches of wild A. fulica from Florianópolis, state of Santa Catarina, Brazil: only 1 out of 244 animals were infected with metastrongylid larvae. Taken together these data indicate that the giant African snail occurring in Southern Brazil is not a permissive host for both Angiostrongylus species and does not represent a significant risk for transmission of these parasites.

Key words: Angiostrongylus cantonensis - Angiostrongylus costaricenis - Achatina fulica - experimental infection - Brazil

Angiostrongylus cantonensis in Asia and Pacific Islands, and A. costaricensis in Americas are metastrongylid intra-arterial nematodes hosted by rodents that can cause eosinophilic meningo-encephalitis and abdominal angiostrongyliasis, respectively. Human accidental infection may occur after ingestion of L3 eliminated from their intermediate mollusk hosts. The main intermediate hosts for $A$. costaricensis are slugs from Veronicellid family while Achatina fulica, the giant African snail, is considered one of the most important hosts for $A$. cantonensis (Alicata 1965, Morera 1973).

A. fulica has been introduced in Brazil as an alternative for Helix aspersa at "mollusk farms" providing the escargot for traditional French cuisine (Teles et al. 1997). Many of those farms have abandoned A. fulica breeding for economic reasons, the snails have been released into natural environment and they are currently found in huge numbers at many places across the country, from Manaus in Amazonic Region to the state of Santa Catarina in Southern Brazil.

Besides the environmental problems, with many infested urban areas, potential invasion of sylvatic areas and huge proliferation and competition with endemic mollusk fauna, there has been growing concern about the possibility of transmission of $A$. costaricensis and the establishment of A. cantonensis in Brazil.

Our objective is to describe aspects of the susceptibility of $A$. fulica in experimental infection with

Corresponding author and recipient of a CNPq PQI-D fellowship and grant 477782. E:mail: graeteix@pucrs.br

Received 5 June 2006

Accepted 4 October 2006 both $A$. costaricensis and $A$ cantonensis. Data about occurrence of natural metastrongylid infection in giant African snails from Florianópolis, state of Santa Catarina, are also presented.

\section{MATERIALS AND METHODS}

Parasites and snails - The metastrongylid worms are maintained in the laboratory by passages through rodents and Biomphalaria glabrata, Esteio strain, respectively as follows: $A$. costaricensis, Santa Rosa strain: Olygorizomis nigripes and A. cantonensis, Akita strain: Rattus norvergicus. First stage larvae (L1) were isolated from the rodent feces by the Baermann method. Snails both from a breeding farm (bred Af $=b A f)(C A F$ Funcia, Bragança Paulista, SP, Brazil) with weights of $28.5 \mathrm{~g} \pm 7.08$ (medium \pm standard deviation) and from suburban areas (wild Af $=$ wAf) of Santa Catarina Island,

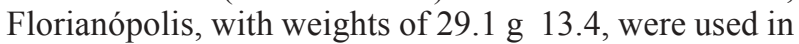
the experiments. Five specimens of each group were studied and identified as Achatina fulica Bowdich, 1822 by Dr Silvana Thiengo (Departamento de Malacologia, Instituto Oswaldo Cruz, Rio de Janeiro). As negative control groups, 12 bAf and 20 wAf were kept in the same conditions of the experimental groups.

Experimental infection - Groups of 5 animals were exposed to $1 \times 10^{3}, 5 \times 10^{3}$ and $10 \times 10^{3} \mathrm{~L} 1$ by ingestion or inoculation into a hole in the shell. For the "ingestion" mode of infection the snails were fasted for 4 days before exposure. A small fragment of lettuce containing a small amount of normal rodent feces was placed on the center a $400 \mathrm{~cm}^{2}$ glossy cellophane paper and the L1 suspension was placed on top of the feces immediately before placing the snail nearby. The snails ate the contaminated food under direct and continuous observation and the cellophane paper was examined under a stereo-microscope for subtraction of the number of larvae lost during the 
exposure and a more strict estimation of the inocula. For the inoculation mode of infection, the shell was washed and perforated next to its last whorl using a 1.5 $\mathrm{mm}$ diameter steel drill (HP1500K Makita, SJ dos Campos, Brasil, www.makita.com.br). The larvae suspension was inoculated into the visceral mass and the hole was closed with a wax plug (Corfix, Porto Alegre RS) (Figs 1 and 2). The animals were killed at 28 days p.i. and they had their tissues processed in the same methodology used for examination of wild animals and described below.

Collection and examination of wild animals - The snails were collected in several localities (Saco Grande, Monte Verde, Vargem Grande, Ingleses, and Rio Vermelho) by the staff of the public health service of Florianópolis, Brazil. Collection was performed by a diurnal search, the animals were kept in large plastic boxes and sent to the laboratory. Parasitological examination of the animals was performed as follows: all soft tissues were minced and

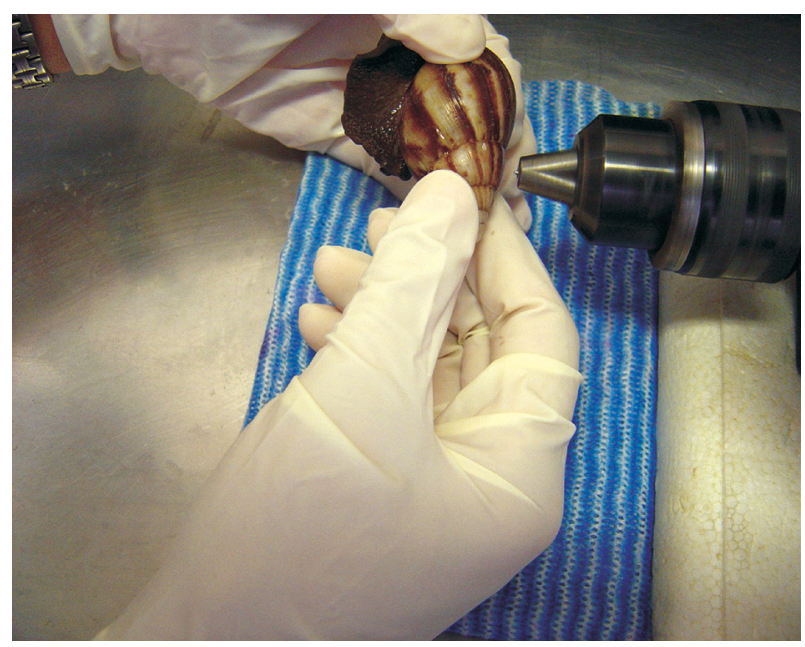

Fig. 1: mode of infection through a hole in the shell of Achatina fulica.

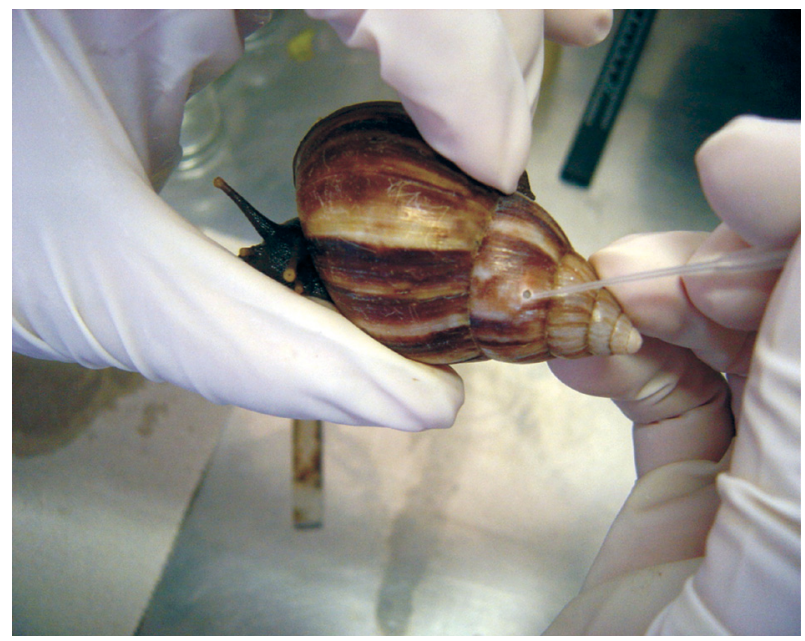

Fig. 2: perforation of the shell. Introduction of a fine plastic tip for inoculation of infective L1. submitted to artificial digestion with a $0.03 \%$ pepsin (Sigma P 7125) solution in $0.7 \% \mathrm{HCl}$ for $2 \mathrm{~h}$ at $37^{\circ} \mathrm{C}$ (modified from Wallace \& Rosen 1969). The resulting preparation was placed in Baermann funnels for isolation of the third stage larvae (L3). They were counted, measured and had their morphology analyzed under a stereomicroscope.

Statistical analysis - Quantitative variables the comparison of media was performed through a variance analysis (ANOVA - SPSS 8.0) with a model of fixed effects and whenever appropriated the Mann-Whitney test was also employed. Qualitative variables were expressed as frequency estimations. Values of $P$ lower than 0.05 were considered as indicators for significance.

Bioethics - Animal handling and experimentation were done in accordance with Brazilian legislation (Lei 6.638, 8 May 1979) and the recommendations from Colégio Brasileiro de Experimentação Animal (Cobea).

\section{RESULTS}

The parasitological examination of wild A. fulica detected only 1 out of 244 individuals infected with metastrongylid larvae, with a low parasitic burden (12 larvae) (Table I).

In experimental exposure of $A$. fulica to $A$. cantonensis or A. costaricensis ingestion was better than inoculation into the visceral mass $(P=0.001)$ to establish infection. No significant difference in the rate of recovery (RR) was detected when species were compared $(P=0.196)$ and RR showed a slight inversal variation when compared to inocula: it was even lower with higher inocula $(10,000$ larvae). Mortality occurred predominantly within the bred A. fulica groups, but most probably linked to the mode of infection through a hole in the shell (Tables II and III).

\section{DISCUSSION}

Besides the huge damage A. fulica has produced in local Brazilian flora and fauna, the data herein presented do not support a significant concern about the possibility of Angiostrongylus spp. transmission: parasitic burden and recovery rate of inocula (RR) were extremely low. Data from animals collected at Santa Catarina Island (Table I) are in accordance with the experimental data: infection with metastrongylid larvae does not appear to

\section{TABLE I}

Metastrongylid larvae recovered from Achatina fulica from Santa Catarina Island, Florianópolis, Brazil

\begin{tabular}{lcc}
\hline Date of sampling & $\begin{array}{c}\text { Molluscs } \\
\text { examined }\end{array}$ & $\begin{array}{c}\text { Number } \\
\text { of larvae }\end{array}$ \\
\hline May/2003 & 34 & 12 \\
August/2003 & 47 & 0 \\
January/2004 & 87 & 0 \\
February/2004 & 33 & 0 \\
March/2004 & 11 & 0 \\
May/2004 & 32 & 0 \\
\hline Total & 244 & 12 \\
\hline
\end{tabular}




\section{TABLE II}

Experimental infection of Achatina fulica with first stage larvae of Angiostrongylus cantonensis by ingestion or inoculation into the visceral mass. Five animals were exposed to each inoculum size $(1000,5000$, and 10,000 larvae)

\begin{tabular}{|c|c|c|c|c|}
\hline \multirow[b]{2}{*}{ L1 inocula } & \multicolumn{2}{|c|}{ Ingestion } & \multicolumn{2}{|c|}{$\begin{array}{l}\text { Inoculation into } \\
\text { general cavity }\end{array}$} \\
\hline & $\begin{array}{c}\text { Individual } \\
\text { larvae } \\
\text { burden }\end{array}$ & $\begin{array}{c}\text { Recovery } \\
\text { of larvae } \\
(\%)\end{array}$ & $\begin{array}{c}\text { Individual } \\
\text { larvae } \\
\text { burden }\end{array}$ & $\begin{array}{c}\text { Recovery } \\
\text { of larvae } \\
(\%)\end{array}$ \\
\hline \multicolumn{5}{|c|}{ Wild A. fulica } \\
\hline 1000 & $0,0,0,0,0$ & 0 & $0,0,0,0,0$ & 0 \\
\hline 5000 & $0,0,0,0,0$ & 0 & $0,0,0,0,0$ & 0 \\
\hline 10,000 & $0,0,0,0,1$ & 0.01 & $0,0,0,0,0$ & 0 \\
\hline \multicolumn{5}{|c|}{ Bred A. fulica } \\
\hline 1000 & $5,0,1,0,0$ & 0.6 & $0,0,0,0$, 出 & 0 \\
\hline 5000 & $5,0,0,0,0$ & 0.1 & $0,0,0,0,0$ & 0 \\
\hline 10,000 & $0,1,3,4,0$ & 0.08 & 0 , 出, 0,0 , ↔ & 0 \\
\hline
\end{tabular}

§: the mollusk died preventing evaluation.

\section{TABLE III}

Experimental infection of Achatina fulica with first stage larvae of Angiostrongylus costaricensis, by ingestion or inoculation into the visceral mass. Five animals were exposed to each inoculum size (1000, 5000, and 10,000 larvae)

\begin{tabular}{|c|c|c|c|c|}
\hline \multirow[b]{2}{*}{ L1 inocula } & \multicolumn{2}{|c|}{ Ingestion } & \multicolumn{2}{|c|}{$\begin{array}{c}\text { Inoculation into } \\
\text { general cavity }\end{array}$} \\
\hline & $\begin{array}{c}\text { Individual } \\
\text { larvae } \\
\text { burden }\end{array}$ & $\begin{array}{c}\text { Recovery } \\
\text { of larvae } \\
(\%)\end{array}$ & $\begin{array}{c}\text { Individual } \\
\text { larvae } \\
\text { burden }\end{array}$ & $\begin{array}{c}\text { Recovery } \\
\text { of larvae } \\
(\%)\end{array}$ \\
\hline \multicolumn{5}{|c|}{ Wild A. fulica } \\
\hline 1000 & $0,0,0,0,0$ & 0 & $0,0,0,0,0$ & 0 \\
\hline 5000 & 0,0 , 出, 0,2 & 0.04 & $0,0,0,0,0$ & 0 \\
\hline 10,000 & $0,0,0,0,3$ & 0.03 & $0,2,0,0,0$ & 0.02 \\
\hline \multicolumn{5}{|c|}{ Bred A. fulica } \\
\hline 1000 & $3,0,0,0,0$ & 0.3 & 0,出,↔, 0,0 & 0 \\
\hline 5000 & $0,0,0,0$, 色 & 0 & 0,虫, 0 ,出 & 0 \\
\hline 10,000 & $1,1,0,0,2$ & 0.03 & 0 ,, 0, 中, 0 & 0 \\
\hline
\end{tabular}

↔: the mollusk died preventing evaluation.

be a significant problem in natural populations of the giant snail.

It has previously been reported that $A$. fulica is susceptible to infection with $A$. costaricensis, showing highly variable numbers of L3 and that most of the animals did not get infected (Carvalho et al 2003).

Evaluation of the epidemiological importance of a given species as host and vector for a parasite requires more than the demonstration of susceptibility (Prociv et al. 2000). Detailed evaluation of the amount of resulting parasitic burden, the dispersion estimatives of its values and the yield of exposure (the rate of recovery,

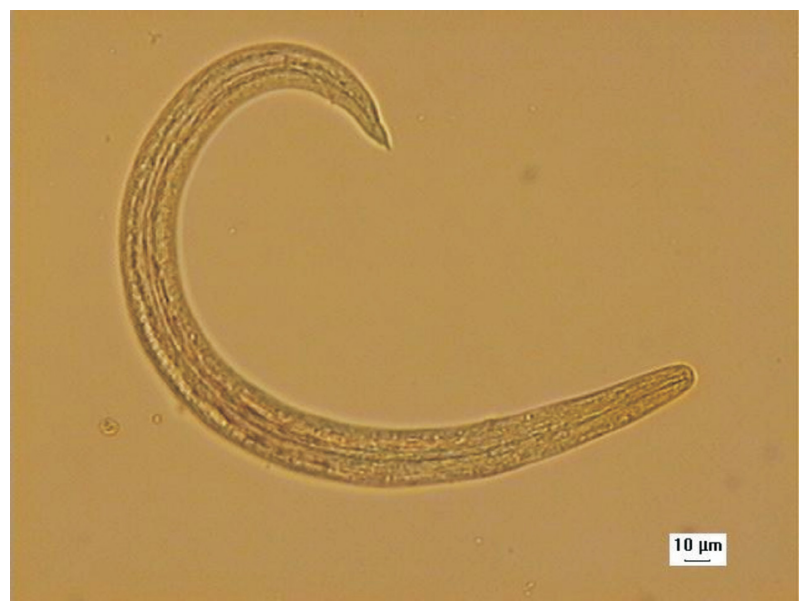

Fig. 3: third stage larvae of $A$. costaricensis. Note the sub-terminal notch that indicates a probable identification of Angiostrongylus spp. See Morera (1973) to visualize lucida camera drawings of $A$. costaricensis' L3.

RR: recovered larvae/inoculum) are essential to address the issue. To generate these data, a very strict control of the inocula is necessary, including the evaluation of larvae lost when the animals are exposed to contaminated food in order to let a spontaneous ingestion as way of infection. The evaluation of a more invasive approach, like the inoculation of the larval suspension into the general cavity through an artificial hole in the shell proved unnecessary since a satisfactory control of inocula was possible through careful washing of the animals and the cellophane paper used underneath the animals while they were ingesting the contaminated food. The significant difference of RR favoring ingestion may indicate the artificiality of the introduction of larvae through a hole into the general cavity.

It is known that metastrongylid larvae may actively penetrate through the tegument (Thiengo 1996) what may have occurred in the "ingestion" mode of infection in the experiments now reported, but we suppose most of the larvae were effectively ingested because of the voracity of the snails to ingest the contaminated food.

Mortality occurring predominantly in A. fulica bred in captivity when compared to wild $A$. fulica may indicate selection of a host population prone to a higher morbidity when infected with A. costaricensis or A. cantonensis. Giant African snail in Asia is probably much more permissive than the recently introduced populations in South America, as indicated by high prevalence and parasitic burden in naturally infected animals, e.g. in Thailand (Pipitgool et al. 1997).

In conclusion, the present data does not support the hypothesis that A. fulica occurring in Southern Brazil poses a significant threat to human health. Epidemiological surveillance is otherwise recommended due to the possibility of introduction of $A$. cantonensis as previously reported for Central and North America (Aguiar et al. 1981, Anderson et al. 1986, Campbell \& Little 1988). 


\section{ACKNOWLEDGMENTS}

To Dr Kentaro Yoshimura (Department of Parasitology, Akita University Medical School, Japan) for providing the Akita strain of A. cantonensis; Dr Silvana Carvalho Thiengo (Department of Malacology, Instituto Oswaldo Cruz, Rio de Janeiro, Brazil), for identification of the snails; the staff at public health services at municipality of Florianopolis, for continuous support for lab and field work.

\section{REFERENCES}

Aguiar PH, Morera P, Pascual J 1981. First record of $A$. cantonensis in Cuba. Am J Trop Med Hyg 30: 963-965.

Alicata JE 1965. Biology and distribution of the rat lungworm, Angiostrongylus cantonensis, and its relationship to eosinophilic meningoencephalitis and other neurological disorders of man and animals. Adv Parasitol 3: 223-248.

Anderson E, Gubler DJ, Sorenson K, Beddard J, Ash LR 1986. First report of Angiostrongylus cantonensis in Puerto Rico. Am J Trop Med Hyg 32: 319-322.

Campbell BG, Little MD 1988. The finding of Angiostrongylus cantonensis in rats in New Orleans. Am J Trop Med Hyg 38: 568-573.

Carvalho OS, Teles HMS, Mota EM, Mendonça CLGF, Lenzi
HL 2003. Achatina fulica Bowdich, 1822 (Mollusca: Gastropoda) como hospedeiros intermediário potencial do Angiostrongylus costaricensis Morera \& Céspedes 1971. Rev Soc Bras Med Trop 36: 743-745.

Morera P 1973. Life history and redescription of Angiostrongylus costaricensis Morera and Céspedes, 1971. Am J Trop Med Hyg 22: 613-621.

Pipitgool V, Sithithawom P, Hinz E 1997. Angiostrongylus infections in rats and snails in Northeast Thailand. Southeast Asian JTrop Med Public Health 28: 190-193.

Prociv P, Spratt DM, Carlisle MS 2000. Neuro-angiostron-gyliasis: unresolved issues. Int J Parasitol 30: 1295-1303.

Teles HMS, Vaz JF, Fontes LR, Domingos MF 1997. Registro de Achatina fulica Bowdich, 1822 (Mollusca, Gastropoda) no Brasil: caramujo hospedeiro intermediário da angiostrongilíase. Rev Saúde Pública 31: 310-312.

Thiengo SC 1996. Mode of infection of Sarasinula marginata (Mollusca) with larvae of Angiostrongylus costaricensis (Nematoda). Mem Inst Oswaldo Cruz 91: 277-278.

Wallace GD, Rosen L 1969. Techniques for recovering and identifying larvae of Angistrongylus cantonensis. Malacologia 7: $427-438$. 